\title{
ANATOMIA DA MADEIRA DO ANGICO BRANCO, Albizia austrobrasilica Burk.
}

\author{
José Newton Cardoso Marchiori \\ Departamento de Ciências Florestais - Centro de Ciências Rurais \\ UFSM - Santa Maria, RS
}

\section{RESUMO}

São descritos os caracteres anatômicos da madeira de Albizia austrobrasilica Burk. e fornecidas fotomicrografias de sua estrutura.

Os principais caracteres observados, tais como elementos vasculares muito curtos, placas de perfuração simples, parênquima axial paratraqueal, raios homogêneos e fibras libriformes, atestam um alto grau de especialização do xilema. Para a identificação da madeira são também importantes a presença de fibras septadas, de pontuações intervasculares ornamentadas e a ausência de estratificação.

Palavras-chave: Anatomia da madeira, Albizia, Albizia austrobrasilica Burk., Leguminosae, Mimosaceae.

\section{SUMMARY}

The wood anatomy of Albizia austrobrasilica Burk. is described and photomicrographs of its structure are furnished.

Very short vascular elements, simple perforation plates, paratracheal axial parenchyma, homogeneous rays and libriform fibres, are the most important features in the wood anatomy. These aspects are common among the Leguminosae and indicate a high level of wood $s_{k}$ ecialization. Septated fibres, vestured pits and the absence of any kind of storied arrangement of cells (ripple marks), are also important to the identification of this wood.

Keywords: Wood Anatomy, Albizia, Albizia austrobrasilica, Leguminosae, Mimosaceae 


\section{INTRODUÇÃo}

A flora brasileira é uma das mais ricas do mundo e conta com numerosas espécies de grande potencial econômico, ainda praticamente desconhecidas. $\mathrm{O}$ estudo deste material é importante para a valorização de nossas matas nativas, para seu aproveitamento mais racional e para o abastecimento de um mercado cada vez mais carente de madeiras, derivados e outros produtos de origem florestal.

Mesmo em estados como o Rio Grande do Sul, com sólida tradição no estudo da Botânica, ainda se encontram espécies promissoras que carecem de investigação sobre a anatomia e propriedades de seu lenho.

O angico branco - Albizia austrobrasilica Burk. - é um bom exemplo da situação acima exposta. Apesar do grande porte alcançado pelos indivíduos adultos, que compartilham o dossel superior das matas nativas da bacia do Rio Uruguai, fralda da Serra Geral e mata pluvial da encosta atlântica, esta espécie era inclusive desconhecida pela ciência até o ano de 1979, quando foi descrita por Arturo Burkart, eminente leguminólogo argentino.

Observações de cunho florestal, realizadas no município de Santa Maria, indicaram que os individuos adultos produzem troncos de grandes dimensões e com boas perspectivas de utilização. O presente estudo visa a análise dos caracteres gerais, macroscópicos e microscópicos de sua madeira, com vistas à identificação e reconhecimento de espécies afins. Estas informações são básicas para o estudo tecnológico da espécie, para o processamento adequado de sua madeira e correta utilização.

\section{REVISÃO DE LITERATURA}

O gênero Albizia Durazzini reúne cerca de 150 espécies (SCHULTZE-MOTEL, 1964; NIELSEN, 1981), tendo distribuição predominantemente paleotropical e escassos representantes na América quente. São árvores geralmente inermes, de folhas bipinadas e com flores tubulosas, dispostas em capitulos ou racemos espiciformes. Os estames são numerosos e soldados em sua base, formando um curto tubo. Os frutos são legumes retos, comprimidos, secos e de consistência papirácea ou apergaminhada (BURKART, 1978).

Albizia austrobrasilica é espécie relativamente nova para a ciência, tendo sido descrita por BURKART (1979), em fascículo da "Flora Ilustrada Catarinense". É interessante destacar que apesar de não ser rara no Rio Grande do Sul, a espécie nunca havia sido referida em trabalhos clássicos da Botânica regional , tais como em RAMBO (1953, 1956, 1966) e SCHULTZ 
(1975). Na região central do Estado, é bastante comum nas matas que revestem a encosta da Serra Geral, aparecendo ainda com freqüência em jardins e terrenos incultos.

BURKART (1979) reconhece outras duas espécies nativas de Albizia para o Rio Grande do Sul, freqüentemente atribuídas na literatura ao gênero Pithecellobium (Albizia niopoides e A. polycephala). Dentre as espécies ornamentais de Albizia cultivadas na região, destacam-se a acácia-de-Constantinopla (Albizia julibrissin), o ébano-oriental (Albizia lebbeck) e a Albizia lophantha.

A espécie a ser estudada tem porte arbóreo e mais de $15 \mathrm{~m}$ de altura, com longo e robusto fuste reto. Floresce em novembro, apresentando frutos maduros de fevereiro até março.

KLEIN (1979) define Albizia austrobrasilica como espécie heliófila e seletiva higrófita, que prefere o interior da mata primária, a margem de rios ou pequenas depressões do terreno, além de matas de várzea e capoeiras. Em levantamento florístico do Parque Estadual do Turvo, RS, BRACK et al. (1985) indicam como habitats preferenciais da mesma, tanto o interior como a beira da mata.

KLEIN (1979) considera que a espécie teve possivelmente uma distribuição muito mais ampla no passado, permanecendo atualmente como rélito no alto vale do Itajaí, bem como na ilha de Santa Catarina. Em sua imigração a partir do oeste, o mesmo autor reconhece duas rotas distintas : pelo rio Iguaçú-Itajai e através da Depressão Central do Rio Grande do Sul.

KLEIN, (1979) atribui à Albizia austrobrasilica o nome comum de "pau-gambá", termo contudo desconhecido pela população no Rio Grande do Sul.

A espécie apresenta folhas alternas de até $40 \mathrm{~cm}$ de comprimento, compostas por 610 jugos. As pinas, com 6-16 cm de comprimento, reúnem de 23 a 30 pares de folíolos discolores, retos ou sub-falcados, acuminados, de 10 a $16 \mathrm{~mm}$ de comprimento, com nervura principal excêntrica e 2-3 nervuras basais. O peciolo exibe pequena glândula globosa, séssil e circular. As flores brancas reúnem-se em capitulos, agrupados em paniculas terminais menores do que as folhas. Os pedúnculos medem até $3 \mathrm{~cm}$ de comprimento. O cálice é pubescente, de 1 a $2 \mathrm{~mm}$; a corola é um pouco mais longa $(3 \mathrm{~mm})$ e os estames exsertos alcançam $15 \mathrm{~mm}$ de comprimento. $O$ fruto é um legume reto, comprimido e de consistência papirácea, com $12-18 \mathrm{~cm}$ de comprimento por $2-3 \mathrm{~cm}$ de largura. As sementes são ovais, comprimidas, de aproximadamente 1,1 por $0,6 \mathrm{~cm}$ (BURKART, 1979).

Segundo o sistema de BENTHAM (1876), Albizia austrobrasilica deve ser incluída na secção Samanea e série Parviflorae. É espécie muito próxima à Albizia polycephala (= 
Pithecellobium polycephalum Benth.), da qual difere principalmente pelas inflorescências mais curtas do que as folhas, frutos glabros e lustrosos e foliolos de maior tamanho (BURKART, 1979).

Os estudos de cunho tecnológico e referências anatômicas são sumamente escassos para as madeiras do gênero Albizia.

RECORD \& HESS (1949) relacionaram alguns aspectos gerais, como cerne de cor marrom-amarelado, alburno amarelado e não demarcado com nitidez, brilho mediano até elevado e ausência de gosto ou odor característicos. As madeiras são ainda descritas como pesadas, flexíveis e resistentes, de textura média a grossa, de fácil trabalhabilidade e com durabilidade natural aparentemente baixa. Os autores observam que apesar das cerca de 20 espécies ocorrentes na América tropical incluirem árvores bastante grandes e de ocorrência dispersa na floresta, a madeira é pouco atrativa, sendo utilizada localmente para diversos fins, mas sobretudo em construções.

Com relação às propriedades fisico-mecânicas da madeira, estudos preliminares realizados em Albizia austrobrasilica indicaram um peso específico médio e boa estabilidade dimensional, aspectos que recomendam a realização de uma investigação tecnológica mais detalhada, tendo em vista sua utilização potencial para fins nobres, como a construção civil e mobiliário (SANDRIM, 1990).

Quanto aos aspectos anatômicos da madeira, METCALFE \& CHALK (1972) referem que algumas espécies de Albizia apresentam vasos com mais de $200 \mu \mathrm{m}$ de diâmetro, porosidade semi-difusa, e poros dispostos em padrão oblíquo ou em linhas tangenciais. O parênquima axial é geralmente vasicêntrico, havendo arranjo terminal para poucas espécies. $U$ padrão difuso normalmente é cristalífero e subdividido em câmaras. O parênquima é descrito como seriado, embora células fusiformes sejam comuns em certas espécies. Para Albizia antunesiana Harms, por exemplo, os mesmos autores referem parênquima raro ou ausente.

De acordo com METCALFE \& CHALK (1972) algumas espécies de Albizia possuem raios com até 4-7 células de largura. As fibras são descritas como tipicamente septadas e de paredes finas em algumas espécies.

Com relação à Taxonomia da Madeira, BARETTA-KUIPERS (1981) discorda de NIELSEN (1981) quanto à inclusão em Albizia dos gêneros Pseudosamanea, Macrosamanea e Pithecellobium secção Chloroleucon, por considerar a estrutura da madeira nestes táxones incompativel com Albizia. A fronteira entre Enterolobium e Albizia, por sua vez, tida por NIELSEN (1981) como muito vaga, foi também assim considerada por BARETTA-KUIPERS (1981), sob o prisma da Anatomia da Madeira. A autora observa ainda que a presença de fibras 
septadas na tribo Ingeae, é característica peculiar dos gêneros Albizia e Cathormion, tendo ocorrência apenas ocasional em Arthrosamanea.

\section{MATERIAL E MÉTODOS}

O material a ser estudado foi obtido em uma propriedade vizinha ao Campus da UFSM, em área florestal classificada como "selva da fralda da serra geral " (RAMBO, 1956), da "bacia do rio Jacui" (REITZ et alii, 1983), ou "floresta estacional decidual (VELOSO \& GÓES FILHO, 1982). Consiste de discos de madeira e exsicatas botânicas provenientes de 3 árvores adultas, de boa forma e estado fitossanitário.

O material para os estudos anatômicos foi retirado da região mais externa do alburno, com vistas à evitar o lenho juvenil. Foram preparados 3 bloquinhos de cada amostra, orientados respectivamente para obtenção de cortes anatômicos nos planos transversal, longitudinal radial e longitudinal tangencial. Os bloquinhos foram amolecidos por fervura em água e cortados em micrótomo de deslizamento, com espessura nominal de $18 \mu \mathrm{m}$. Usou-se tripla coloração, com acridina-vermelha, crisoidina e azul-de-astra (DUJARDIN, 1964), diafanização com xilol e montagem permanente com "Entellan".

Para o preparo de lâminas de macerado procedeu-se à desintegração de finos palitos com solução de Jeffrey (FREUND, 1970), coloração da pasta obtida por safranina, desidratação em série alcoólica, diafanização com xilol e o mesmo meio de montagem anteriormente citado.

As descrições anatômicas seguiram as normas da COPANT (1973), com as alterações recomendadas por MARCHIORI (1980) e MUÑIZ (1986). Os dados quantitativos são apresentados na Tabela 1. As fotomicrografias foram tomadas em aparelho Carl Zeiss, com diferentes aumentos.

\section{DESCRIÇÃO DA MADEIRA}

Vasos: Pouco freqüentes (2 - 3,5 - 5/mm), ocupando cerca de 5,7\% da seç̧ão transversal da madeira. Vasos em distribuição difusa e uniforme nos anéis de crescimento. Poros principalmente solitários ou em múltiplos radiais de 2 a 4 (Figura 1.A). Vasos muito curtos (140 - $247-380 \mu \mathrm{m}$ ), de diâmetro médio $(92,5-143-213 \mu \mathrm{m})$, com secção oval e paredes espessas $(3,7-4,9-6,3 \mu \mathrm{m})$. Placas de perfuração simples, transversais ao vaso ou levemente obliquas (Figura 1.B). Apêndices 
ausentes ou então curtos $(10-31-82 \mu \mathrm{m})$, dispostos em uma ou em ambas as extremidades. Espessamentos espiralados e outras estriações, ausentes.

Pontuações intervasculares de diâmetro pequeno a médio $(7,5-8,3-10 \mu \mathrm{m})$, em arranjo alterno e de forma poligonal. Abertura lenticular, inclusa, horizontal e ornamentada.

Pontuações raio-vasculares pequenas $(5-7,5-9,5 \mu \mathrm{m})$ e ornamentadas (Figura 2.B-C). Pontuações parênquimo-vasculares de diâmetro pequeno a médio $(6-8-9 \mu \mathrm{m})$, semelhantes às anteriores (Figura 1.C-D).

Parênquima axial : Abundante, ocupando cerca de $18,5 \%$ do volume da madeira e em disposição paratraqueal, predominantemente aliforme (Figura 1.A-B). São também comuns as confluências de parênquima. Encontram-se ainda células parenquimáticas axiais associadas ao limite de anel de crescimento (apotraqueal marginal) e dispersas no meio do tecido fibroso (apotraqueal difuso), sendo nestes casos normalmente cristalifero (Figura 2.D). O parênquima axial não é estratificado. Parênquima seriado, com 240 - 376 - $555 \mu \mathrm{m}$ de altura por 13,7 - 24,5 - $35 \mu \mathrm{m}$ de largura, sendo composto por 2 a 4 células retangulares (Figura 2.A-C).

As séries cristalíferas compõem-se de 15 a 25 câmaras, cada uma com um cristal prismático de oxalato de cálcio (Figura 2.D).

Raios: Pouco numerosos (4-6-8/mm), representando cerca de $8,9 \%$ do volume da madeira. Tecido radial homogêneo, composto inteiramente de células horizontais (Figura 1.C). Raios de tipo normal; raios agregados e fusionados, ausentes (Figura 2.A-C).

Raios unisseriados muito escassos $(2,7 \%)$, muito baixos $(12,5-84-165 \mu \mathrm{m})$, extremamente finos $(6,2-11-32,5 \mu \mathrm{m})$ e com $1-6$ - 13 células de altura.

Raios multisseriados geralmente com 3 células de largura $(68,1 \%$ ) (Figura 2.A-C), menos comumente bisseriados $(29,2 \%)$; de muito baixos a baixos (120 - $202-300 \mu \mathrm{m})$, com $8-15-22$ células de altura e muito finos $(11,2-21,4-37,5 \mu \mathrm{m})$.

As células radiais tem forma oval, quando vistas em plano tangencial (Figura 2.A-C). Células eretas, quadradas, latericuliformes, oleiferas, envolventes, mucilaginosas e cristais, ausentes no tecido radial (Figura 1.C-D).

Fibras: Ocupando cerca de $67 \%$ do volume da madeira. Fibras libriformes, septadas (Figura 2.D) e eralmente gelatinosas, providas de diminutas pontuações simples. Fibras de muito curtas a curtas $750-946-1.130 \mu \mathrm{m})$, estreitas $(10-16,1-25 \mu \mathrm{m})$ e de paredes delgadas $(1,8-4,7-6,9 \mu \mathrm{m})$. 
Outros caracteres: Canais secretores, tubos laticíferos e taniniferos, líber incluso, máculas medulares e estratificação, ausentes.

Anéis de crescimento de dificil reconhecimento microscópico, marcados fracamente por fibras septadas e gelatinosas de lume mais estreito, associadas a séries cristaliferas de parênquima axial (Figura 1.A).
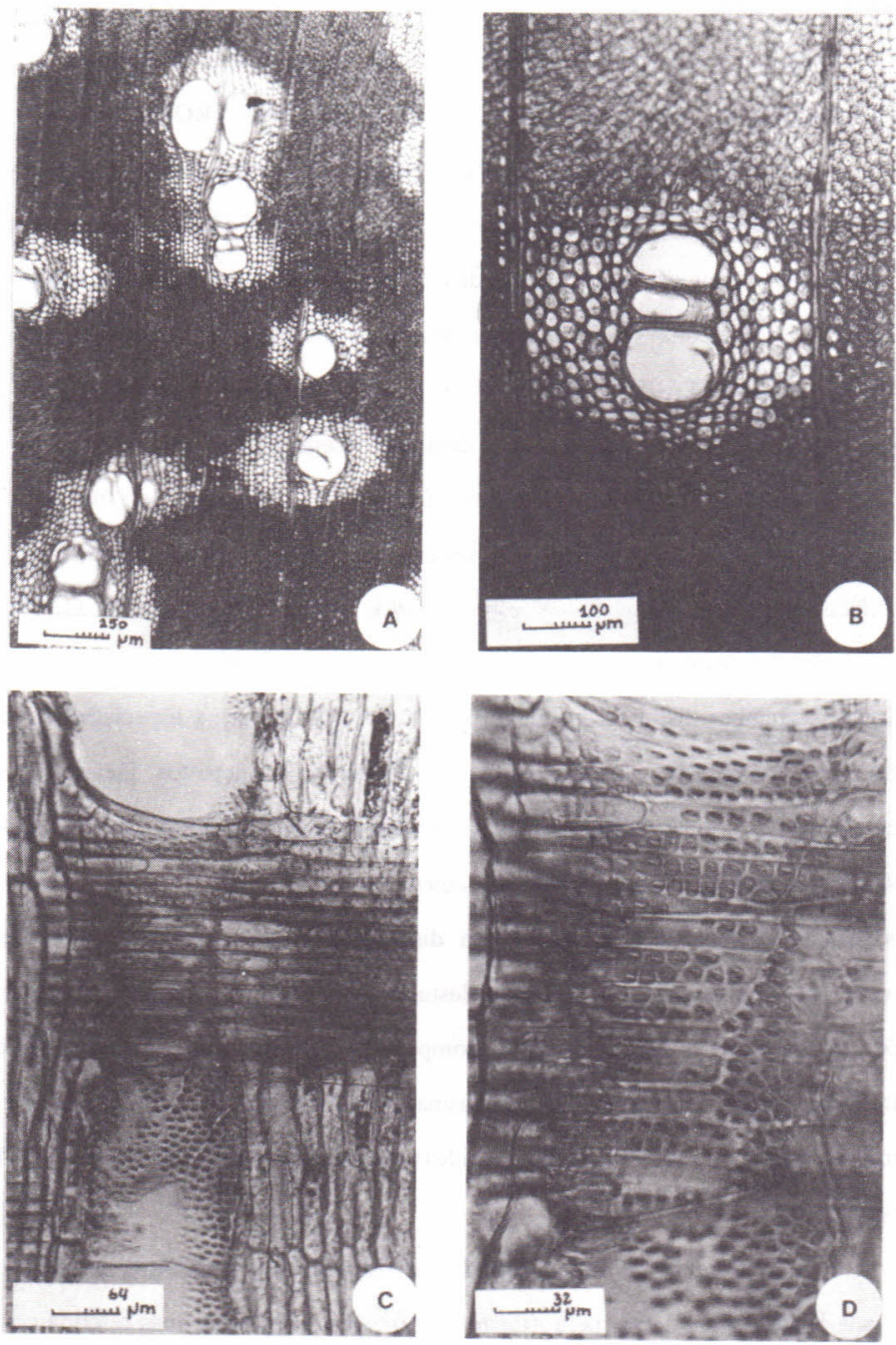

FIGURA 1. Aspectos anatômicos da madeira. A. Secção transversal, mostrando o limite de anel de crescimento, poros, parênquima paratraqueal e fibras. B. Detalhe da seç̧ão transversal, com parênquima aliforme e placa de perfuração simples no vaso mediano. C. Raio homogênero e vaso, em corte longitudinal radial. D. Detalhe do pontuado raio-vascular, em seç̧ão longitudinal radial. 


\section{ANÁLISE DA ESTRUTURA ANATÔMICA}

Os principais caracteres anatômicos da madeira de Albizia austrobrasilica Burk., tais como elementos vasculares muito curtos, placas de perfuração simples, pontuações intervasculares ornamentadas, parênquima paratraqueal e fibras libriformes, apresentam uma ocorrência generalizada na familia Leguminosae (METCALFE \& CHALK, 1972; RECORD \& HESS, 1949; COZZO, 1950,51) e indicam um elevado grau de especialização filogenética (BAILEY, 1953; BARETTA-KUIPERS, 1981; DICKISON, 1975; EAMES, 1961; FROST, 1930).

A estrutura anatômica dos raios também demonstra tal especialização do xilema, de acordo com os critérios de BARGHOORN $(1940,41)$ e KRIBS (1935). A ocorrência exclusiva de raios homogêneos, compostos tipicamente de células procumbentes, é considerada por METCALFE \& CHALK (1972) como indicadora de alta especialização e tida como muito peculiar à Mimosoideae. BARETTA-KUIPERS (1980, 81), a este respeito, considera que a estrutura radial da madeira desta sub-familia é a mais evoluída dentro das Leguminosas.

A ausência de qualquer forma de estratificação na madeira, caráter inquestionavelmente pouco evoluído, tem, no caso de Albizia austrobrasilica, um significado mais taxonômico do que filogenético. A este respeito, BARETTA-KUIPERS (1981) opina que a especialização das leguminosas, a partir da relativamente primitiva sub-família Caesalpinioideae, seguiu duas caminhos distintos: em direção à Mimosoideae, com a especialização dos raios e em direção à Papilionoideae, com a estratificação de todos os elementos. De acordo com a mesma autora, este aspecto, juntamente com a homogeneidade do tecido radial, permitem colocar a espécie em estudo na sub-família Mimosoideae de Leguminosae.

A abundância do parênquima axial e sua disposição paratraqueal aliforme é também caráter frequente em Leguminosas. Cabe ainda destacar para Albizia austrobrasilica, a presença dos padrões apotraqueais difuso e marginal, compostos neste caso por séries cristalíferas de 15-25 câmaras, cada uma contendo um cristal prismático de oxalato de cálcio. Este aspecto é também bastante freqüente em madeiras de Mimosoídeas, de acordo com COZZO (1951) e METCALFE \& CHALK (1972).

A presença de fibras septadas, registrada para a madeira em estudo, foi também observada por COZZO (1951) para Albizia julibrissin e A. hassleri, mas referida como ausente em Albizia lophanta, pelo mesmo autor. RECORD \& HESS (1949), por sua vez, registraram que a presença deste caráter na tribo Ingeae é peculiar aos gêneros Albizia e Cathormion, mas apenas ocasional em Arthrosamanea. 
Para a identificação da madeira de Albizia austrobrasilica são ainda importantes a predominância de poros solitários de diâmetro médio, a presença de 2 a 4 células no parênquima axial seriado e o pequeno comprimento das fibras.
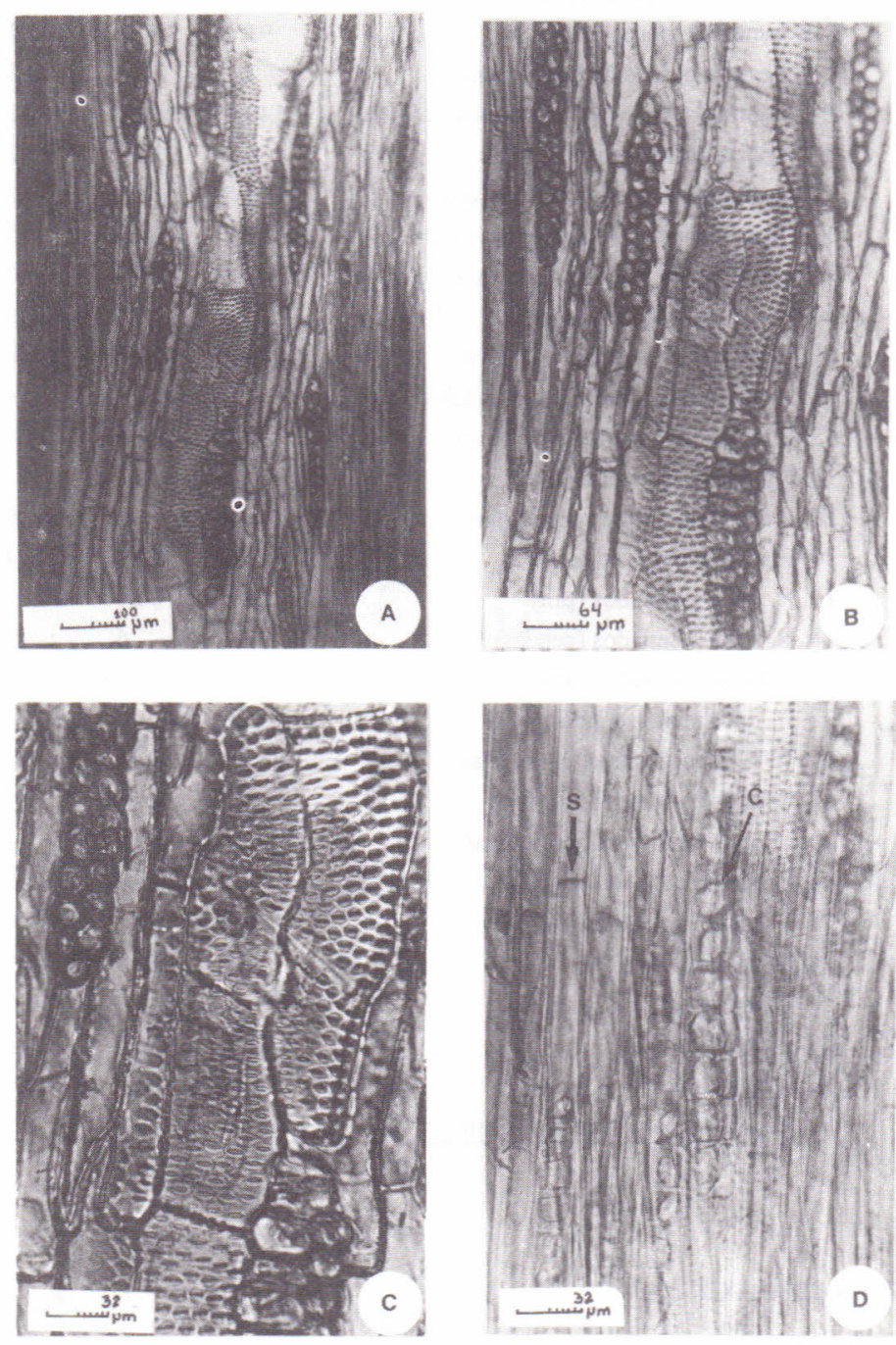

FIGURA 2. Aspectos da secção longitudinal tangencial. A. Raios multisseriados e vaso com parênquima paratraqueal. B. Detalhe do parênquima axial paratraqueal, em séries de 2 células. C. Detalhe das pontuações parênquimo vasculares. D. Fibras septadas $(\mathrm{S})$ e cristais romboédricos em câmaras (C). 
TABELA 1. Dados quantitativos e determinações estereológicas da estrutura anatômica da madeira de Albizia austrobrasilica.

\begin{tabular}{|c|c|c|c|c|}
\hline CARACTERISTICA & V.m. & $\mathrm{X}$ & V.M. & SX \\
\hline 1. Fração de poros (\%) & 3 & 5,7 & 9 & 2,42 \\
\hline 2. Freqüência de poros (poros/mm) & 2 & 3,5 & 5 & 0,77 \\
\hline 3. $\varnothing$ lúmem de poros $(\mu \mathrm{m})$ & 93,0 & 143,0 & 213,0 & 30,54 \\
\hline 4. Espessura parede de poros $(\mu \mathrm{m})$ & 3,7 & 4,9 & 6,3 & 0,70 \\
\hline 5. Comprimento elementos vasculares $(\mu \mathrm{m})$ & 140,0 & 247,0 & 380,0 & 56,40 \\
\hline 6. Comprimento de apêndices $(\mu \mathrm{m})$ & 10,0 & 31,0 & 82,0 & 17,67 \\
\hline 7. $\emptyset$ pontuações intervasculares $(\mu \mathrm{m})$ & 7,5 & 8,3 & 10,0 & 0,62 \\
\hline 8. $\emptyset$ pontuações raio-vasculares $(\mu \mathrm{m})$ & 5,0 & 7,5 & 9,5 & 1,24 \\
\hline 9. $\emptyset$ pontuações parênquimo-vasculares $(\mu \mathrm{m})$ & 6,0 & 8,0 & 9,0 & 0,90 \\
\hline 10. Fração parênquima axial (\%) & 11 & 18,5 & 26,0 & 4,64 \\
\hline 11. H. séries parênquima axial $(\mu \mathrm{m})$ & 240,0 & 376,0 & 555,0 & 72,48 \\
\hline 12. H. séries parênquima axial (células) & 2 & 2,7 & 4 & 0,87 \\
\hline 13. L. séries parênquima axial $(\mu \mathrm{m})$ & 13,7 & 24,5 & 35,0 & 6,38 \\
\hline 14. Fração tecido radial (\%) & 5 & 8,9 & 11 & 2,19 \\
\hline 15. Freqüência de raios (raios/mm) & 4 & 6 & 8 & 1,24 \\
\hline 16. Fração raios 1-seriados (\%) & 2 & 2,7 & 4 & 0,81 \\
\hline 17. H. raios 1-seriados $(\mu \mathrm{m})$ & 12,5 & 84,0 & 165,0 & 33,59 \\
\hline 18. H. raios 1-seriados (células) & 1 & 6 & 13 & 2,61 \\
\hline 19. L. raios 1-seriados $(\mu \mathrm{m})$ & 6,2 & 11,0 & 32,5 & 6,09 \\
\hline 20. H. raios multisseriados $(\mu \mathrm{m})$ & 120,0 & 202,0 & 300,0 & 47,36 \\
\hline 21. H. raios multisseriados (células) & 8 & 15 & 22 & 3,47 \\
\hline 22. L. raios multisseriados $(\mu \mathrm{m})$ & 11,2 & 21,4 & 37,5 & 6,76 \\
\hline 23. L. raios multisseriados (células) & 2 & 2,5 & 4 & 0,50 \\
\hline 24. Fração raios 2-seriados (\%) & 23 & 29,2 & 33,0 & 4,21 \\
\hline 25. Fração raios 3-seriados (\%) & 64 & 68,1 & 75,0 & 4,66 \\
\hline 26. Fração de fibras (\%) & 58 & 66,9 & 74,0 & 5,17 \\
\hline 27. Comprimento de fibras $(\mu \mathrm{m})$ & 750,0 & 946,3 & $1.130,0$ & 110,99 \\
\hline 28. $\varnothing$ de fibras $(\mu \mathrm{m})$ & 10,0 & 16,1 & 25,0 & 3,17 \\
\hline 29. Ø lúmem de fibras $(\mu \mathrm{m})$ & 2,5 & 6,7 & 15,0 & 3,41 \\
\hline 30. Espessura parede de fibras $(\mu \mathrm{m})$ & 1,8 & 4,7 & 6,9 & 1,64 \\
\hline
\end{tabular}

\section{LITERATURA CITADA}

1. BAILEY, I.W. Evolution of the tracheary tissue of land plants. American Journal of Botany, 40: 4-8, 1953.

2. BARETTA-KUIPERS, $T$. The wood structure of leguminous tribes: their characterization by ray and parenchyma features. Forest Products Abstracts, 3(8): 1784, 1980. 
3. BARETTA-KUIPERS, T. Wood Anatomy of Leguminosae: its relevance to Taxonomy. In POLHILL, R.M. \& RAVEN, P.H. Advances in Legume Systematics. 1981. p. 677-715.

4. BARGHOORN, Jr., E.S. The ontogenetic development and phylogenetic specialization of rays in the xylem of Dicotyledons. I. The primitive ray structure. American Journal of Botany, 27: 918-928, 1940.

5. BARGHOORN, Jr., E.S. The ontogenetic development and phylogenetic specialization of rays in the xylem of Dicotyledons. II. Modification of the multiseriate and uniseriate rays. American Journal of Botany, 28: 273-282, 1941.

6. BENTHAM, G. Leguminosae. III. Mimoseae. In: MARTIUS, C.P.F. Flora Brasiliensis. 1876. 15(2): 428 .

7. BRACK, P.; BUENO, R.M.; FALKENBERG, D.B.; PAIVA, M.R.C.; SOBRAL, M. \& STEHMANN, J.R. Levantamento florístico do Parque Estadual do Turvo, Tenente Portela, Rio Grande do Sul, Brasil. Roessleria, 7: 69-94. 1985

8. BURKART, A. Leguminosas. In: DIMITRI, M.J. Enciclopedia Argentina de Agricultura y Jardineria. Buenos Aires, Ed. ACME, 1978. Tomo I: 467-538.

9. BURKART, A. Leguminosas Mimosoideas. In: REITZ, R. Flora Ilustrada Catarinense. Itajaí, 1979. $299 \mathrm{p}$.

10. COPANT COMISION PANAMERICANA DE NORMAS TECNICAS. Descripcion de las caracteristicas generales, macroscopicas y microscopicas. 30:1-019, Santiago, 1973

11. COZZO, D. Anatomia del leño secundario de las leguminosas papilionoideas argentinas silvestres y cultivadas. Rev. del Inst. Nac. de Invest. de las Ciencias Naturales - Ciencias Botanicas, 1(7): 223-361, 1950

12. COZZO, D. Anatomia del leño secundario de las leguminosas mimosoideas y caesalpinioideas argentinas silvestres y cultivadas. Rev. del Inst. Nac. de Invest. de las Ciencias Naturales - Ciencias Botanicas, 2(2): 63-90, 1951.

13. DICKISON, W.C. The bases of Angiosperm Phylogeny. Vegetative Anatomy. Ann. Missouri Bot. Garden, 62: 596 - 620, 1975.

14. DUJARDIN, E.P. Eine neue Holz-zellulosenfaerbung. Mikrokosmos, 53: 94. 1964.

15. EAMES, A.J. Morphology of the Angiosperms. New York, Mc Graw-Hill, 1961. 518 p.

16. FREUND, H. Handbuch der Mikroskopie in der Technik. Frankfurt, Umsham Verlag, 1970. $375 \mathrm{p}$.

17. FROST, F.H. Specialization in secondary xylem of Dicotyledons. I. Origin of vessels. Botanical Gazette, 89: 67-94, 1930 .

18. KLEIN, R.M. Observações ecológicas. In: BURKART, A. Leguminosas Mimosoídeas. Flora Ilustrada Catarinense. Itajai, 1979. p. 110-112.

19. KRIBS, D.A. Salient lines of structural specialization in the wood rays of Dicotyledons. Botanical Gazette, 96: 547-557, 1935.

20. MARCHIORI, J.N.C. Estudo anatômico do xilema secundário e da casca de algumas espécies dos gêneros Acacia e Mimosa, nativas no Estado do Rio Grande do Sul. Curitiba, 1980. 186 f. Dissertação. Mestrado. Universidade Federal do Paraná. Setor de Ciências Agrárias. Curso de Pós-Graduas , em Engenharia Florestal. 
21. METCALfE, C.R. \& CHALK, L. Anatomy of the Dicotyledons. Oxford, Clarendon Press, 1972. $1500 \mathrm{p}$

22. MUÑIZ, G.I.B. de. Descrição da estrutura e ultra-estrutura da madeira de cinco espécies de Prosopis da Argentina e análise da metodologia. Curitiba, 1986. 192 p. Dissertação. Mestrado. Universidade Federal do Paraná. Setor de Ciências Agrárias. Curso de PósGraduação em Engenharia Florestal.

23. NIELSEN, I. Tribe 5. Ingeae Benth. In: POLHILL, R.M. \& RAVEN, P.H. Advances in Legume Systematics. I. England, Royal Botanical Gardens, 1981. p. 173-190

24. RAMBO, B. Estudo comparativo das leguminosas riograndenses. Anais Botânicos, 5:107-184, 1953.

25. RAMBO, B. A Fisionomia do Rio Grande do Sul, Porto Alegre, Selbach, 1956. 443 p.,

26. RAMBO,B. Leguminosae Riograndenses. Pesquisas, Série Botânica, $n^{\circ} 23,1966.166$ p.

27. RECORD, S.J. \& HESS, R.,W. Timbers of the New World. New Haven, Yale University Press, 1949. $640 \mathrm{p}$.

28. REITZ, R \& KLEIN, R.M. \& REIS, A. Projeto Madeira do Rio Grande do Sul.Sellowia, 3435: $1-525,1983$.

29. SANDRIN, A.D. Relatório de Estágio Profissional. Santa Maria, Curso de Engenharia Florestal, 1990. $47 \mathrm{p}$.

30. SCHUltZ, A. Os nomes científicos e populares das plantas do Rio Grande do Sul. Porto Alegre, PUC/EMMA, 1975. $164 \mathrm{p}$.

31. SCHUltZE-MOTEL, W. Reihe Rosales. In : MELCHIOR, H. A. Engler's Syllabus der Pflanzenfamilien. Berlin, Gebrüder Borntraeger, 1964. p. 193-242.

32. VELOSO, H.P. \& GÓES-FILHO, L. Fitogeografia Brasileira: Classificação fisionômicoecológica da vegetação neotropical. Salvador, 1982. RADAMBRASIL, Série Vegetação, $\mathrm{n}^{\circ} 1.80 \mathrm{p}$. 